\title{
Proposal and Evaluation of an Equipment Operating Method Using Solar Radiation Prediction in a Zero Energy House
}

\author{
Reina Oki ${ }^{1, *}$, Yugo Tsuneoka ${ }^{1}$, Shingo Yamaguchi ${ }^{1}$, Soma Sugano $^{1}$, Jun Nakagawa ${ }^{1}$, \\ Naoya Watanabe ${ }^{2}$, Tatsuhiro Kobayashi ${ }^{2}$, Shin-ichi Tanabe ${ }^{1}$, Takashi Akimoto ${ }^{3}$, Yasuhiro Hayashi ${ }^{4}$, and Shinji Wakao $^{4}$ \\ ${ }^{1}$ Department of Architecture, Waseda University, 169-8555 Tokyo, Japan \\ ${ }^{2}$ Asahi Kasei Homes Corporation, 101-8101 Tokyo, Japan \\ ${ }^{3}$ Department of Architecture, Shibaura Institute of Technology, 135-8548 Tokyo, Japan \\ ${ }^{4}$ Department of Electrical Engineering and Bioscience, Waseda University, 169-8555 Tokyo, Japan
}

\begin{abstract}
Because of the increasing promotion of renewable energy such as photovoltaic (PV) panels in Japanese houses, the voltage increase and frequency adjustment of a city electrical distribution network system will be of concern. Therefore, self-consuming surplus electricity and leveling the reverse power flow is important in terms of reducing the smart grid network load and reducing the peak load of the smart grid network. The aim of this study was to acquire knowledge regarding methods of self-consuming surplus power as well as leveling the reverse power flow. An equipment operation method, termed "schedule control," was proposed that changes the operational time of a heat pump water heater and the charging time of a storage battery according to solar radiation prediction. Because PV power fluctuates depending on weather and time zone, this method helps in self-consuming as much PV power generation as possible. By actual measurement and simulation results, it was confirmed that the schedule control of the heat pump water heater and storage battery was useful in self-consuming surplus power and leveling reverse power flow.
\end{abstract}

\section{Introduction}

The final energy consumption in the Japanese housing sector has doubled since the oil crisis, accounting for approximately $15 \%$ of the total. The importance of energy conservation in housing has been reconfirmed by the instability of energy prices and electricity shortages caused by natural disasters in Japan. The Ministry of Economy, Trade and Industry has set a goal of achieving net-Zero Energy Houses (ZEHs) for the majority of ordered detached houses by 2020 [1]. With the increase in ZEHs, the promotion of introducing renewable energy such as photovoltaic (PV) panels in Japanese housings has been remarkable. The number of houses with PV panels installed is predicted to exceed 7.5 million, and the cumulative installed capacity of PV panels is predicted to reach $40 \mathrm{GW}$ in 2030 [2]. Moreover, the Japanese government is attempting to expand the number of installations furthermore and set a goal of introducing 200 GW of PV power generation by 2050 [3], because solar generation is more viable compared to other renewable energies. However, as the number of PV panels increases, there is a concern regarding problems with the voltage increases and frequency adjustment of city electrical distribution networks, caused by the reverse power flow of surplus electric power that cannot be consumed inside the houses. Therefore, urban-scale energy management such as Demand Response and Virtual Power Plant, and also selfconsumption of surplus energy inside houses, will be much more important. In addition, because of the decreasing power sale price following the sequential completion of the Feed-in Tariff from 2019 onwards, consumption of surplus electricity is expected to become economically advantageous. Based on the aforementioned background, it is important to acquire knowledge regarding the methods for self-consumption and leveling of energy supply and demand.

Among the measures promoting ZEHs in Japan is "ENEMANE HOUSE," a competition of ZEHs started in 2014 by the Sustainable Open Innovation Initiative [4]. This competition is a Japanese version of the Solar Decathlon, a collegiate competition of highly efficient and innovative houses hosted by the U.S. Department of Energy [5]. In ENEMANE HOUSE, totally five teams of universities and private enterprises build ZEHs to propose advanced technologies and new means of living ecologically. The indoor environment and energy performance of the houses are measured, and the competition winner is selected according to the measurement results and votes of the juries.

This paper describes the energy management in the ZEH proposed by the team of Waseda University and Shibaura Institute of Technology in ENEMANE HOUSE 2017. Based on the background concerning energy in the Japanese housing sector, the team proposed an energy management aiming for self-consuming as much surplus power as possible and leveling the electrical supply and demand. As the amount of $\mathrm{PV}$ power generation varies depending on weather, the team proposed an equipment control method termed "schedule control," that controls equipment operation according to the amount of solar radiation forecast. 


\section{Test house outline}

Table 1 lists basic information of the test house. Figure 1 shows the $1 \mathrm{~F}$ plan of the test house, and figure 2 shows the electrical system and hot water supply system. The test house is an all electrified, two-story house composed of a steelframe structure, and was built in Osaka, Japan. It is highly insulated with a heat insulation capacity $\left(\mathrm{U}_{\mathrm{A}}\right.$ value $)$ of 0.35 $\mathrm{W} /\left(\mathrm{m}^{2} \cdot \mathrm{K}\right)$. The total floor area is $79.11 \mathrm{~m}^{2}$. Fourteen $\mathrm{PV}$ panels with a total capacity of $3.5 \mathrm{~kW}$ was installed on the south side of the house. It has a lithium ion battery (BT) of $5.6 \mathrm{kWh}$ to which PV power can be charged in a direct current. For a hot water supply system, it uses a solar heat collector and a heat pump water heater (HPWH) in combination. The hot water storage tank of the solar heat collector is connected to the city water flow inlet of the hot water storage tank of the HPWH to reduce the power consumption of the HPWH. Six heat collection panels were connected in parallel and were installed at 0 degrees on the roof surface. Moreover, a Home Energy Management System (HEMS) conforming to the ECHONET-Lite standard was installed to the house, and thus the destination of PV power generation can be controlled. Using HEMS, it is possible to control the operational time of the HPWH and the charging time of the BT.

\section{Control system based on solar radiation forecast}

Figure 3 shows the image of the schedule control. For the purpose of self-consuming surplus power and leveling the energy supply and demand, "schedule control" of HPWH and BT was implemented. Schedule control is a control method that operates equipment according to PV power generation forecast. Schedule control was conducted using the following procedure: First, MesoScale Model Grid Point Value (MSMGPV) [6], a weather forecast data up to 39 hours in advance at a meteorological station $3.3 \mathrm{~km}$ from the test house, was obtained from the Japan Meteorological Agency. Second, a solar radiation forecast up to 39 hours in advance was calculated from the weather forecast data using Just-in-Time Modeling [7]. Just-in-Time Modeling calculates point estimation data of average solar radiation every hour by referring to the database in which past weather data and past solar radiation amount data are associated. Third, the solar radiation forecast was converted into a slope solar radiation forecast using the Erbs model [8]. Fourth, a PV power generation prediction value was calculated from the PV

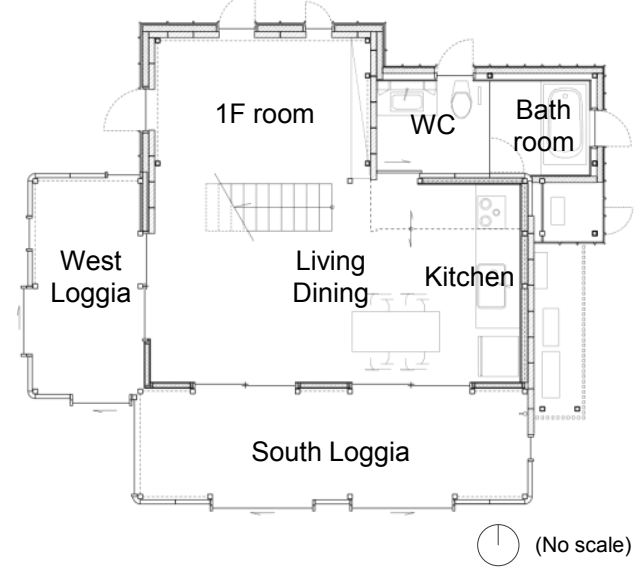

Figure 1. 1F plan of the test house.

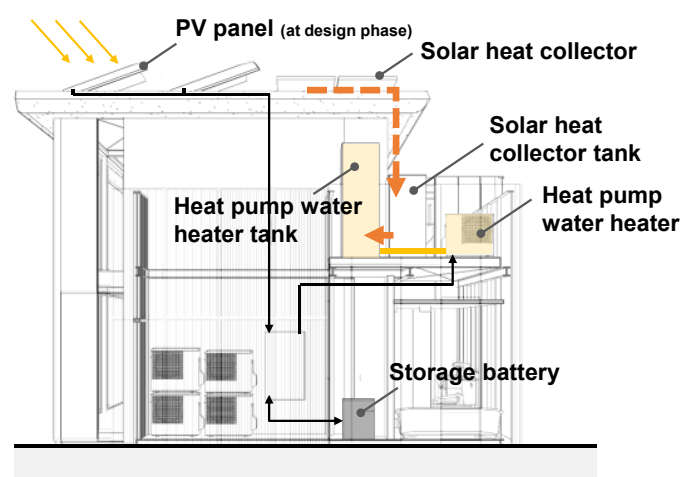

Figure 2. Electrical system and hot water supply system.

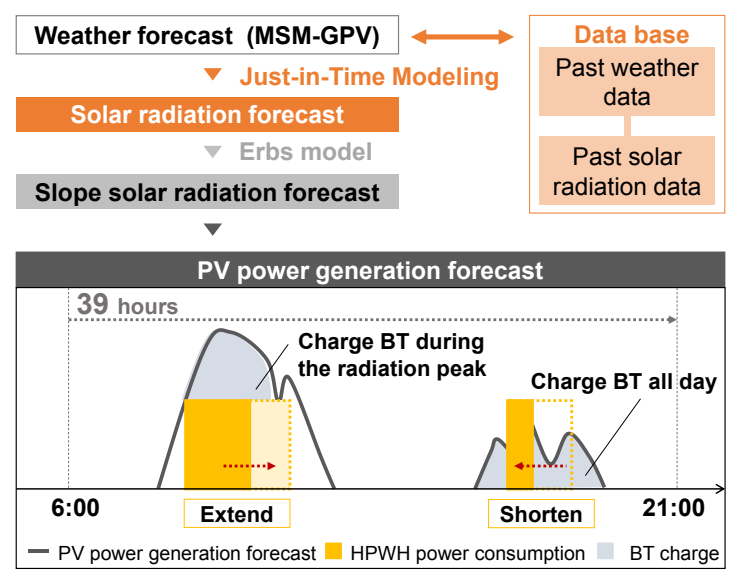

Figure 3. Image of the schedule control.

Table 1. Basic information of the test house.

\begin{tabular}{|c|c|c|c|c|c|}
\hline \multirow{2}{*}{ Photovoltaic module } & Number & Total panel area & $\begin{array}{l}\text { Total maximum } \\
\text { output }\end{array}$ & Installation angle & Conversion efficiency \\
\hline & 14 & $17.9 \mathrm{~m}^{2}$ & $3.5 \mathrm{~kW}$ & 31.0 degrees & $19.5 \%$ \\
\hline \multirow{3}{*}{ Lithium ion battery } & \multicolumn{2}{|c|}{ Electric storage capacity } & Electricity flow & \multicolumn{2}{|c|}{ Input and output rating power } \\
\hline & \multirow{2}{*}{\multicolumn{2}{|c|}{5.6 kWh }} & \multirow{2}{*}{ direct current } & charge & $1.5 \mathrm{~kW}$ \\
\hline & & & & discharge & $2.0 \mathrm{~kW}$ \\
\hline \multirow{3}{*}{ Solar heat collector } & Tank capacity & Total panel area & $\begin{array}{l}\text { Heat collecting } \\
\text { method }\end{array}$ & \multicolumn{2}{|c|}{ Power consumption } \\
\hline & \multirow[b]{2}{*}{$200 \mathrm{~L}$} & \multirow[b]{2}{*}{$11.7 \mathrm{~m}^{2}$} & \multirow[b]{2}{*}{ Forced circulation } & During control & $3.0 \mathrm{~W}$ \\
\hline & & & & $\begin{array}{c}\text { During } \\
\text { heat collection }\end{array}$ & $\begin{array}{c}13.0-75.0 \mathrm{~W} \\
\text { (variable) }\end{array}$ \\
\hline \multirow{3}{*}{$\begin{array}{l}\text { Heat pump water } \\
\text { heater }\end{array}$} & Tank capacity & Boiling temperature & Rating pow & onsumption & Rating capability \\
\hline & \multirow{2}{*}{$370 \mathrm{~L}$} & \multirow{2}{*}{$65.0-90.0^{\circ} \mathrm{C}$} & intermediate period & $0.9 \mathrm{~kW}$ & $4.5 \mathrm{~kW}$ \\
\hline & & & winter & $1.5 \mathrm{~kW}$ & $4.5 \mathrm{~kW}$ \\
\hline
\end{tabular}


module conversion efficiency and the panel area, and was used to decide the operational schedule of HPWH and BT.

The HPWH schedule control targeted the operational starting time and operational total time of the HPWH. The HPWH operational starting time was changed according to the PV power generation prediction of the current day to selfconsume surplus power. The maximum value of the power consumption in the house including the HPWH power consumption was $2 \mathrm{~kW}$, thus the time at which the PV power generation prediction value exceeded $2 \mathrm{~kW}$ was set as the HPWH operational starting time. On a cloudy day when the prediction value was less than $2 \mathrm{~kW}$, the operational time was set according to the time zone where the household electrical load was less (from 13:00). On the other hand, the HPWH operational total time was adjusted according to the PV power generation prediction of the current day and the next day, to reduce the HPWH boiling amount caused by purchase power on a cloudy day. When the amount of PV power generation of the current day was larger than that of the next day, the operational total time of the current day was extended, and when lower, the operational total time of the current day was shortened. The adjustment of the operational total time was carried out within a range that could cover the hot water supply of the current day.

The BT schedule control targeted the charging time of the BT. The charging time was adjusted according to the PV power generation prediction of the current day and the power consumption in the house. To suppress the peak of the sales power after the BT being full, the charging time was shortened particularly during the morning of the day with a large amount of PV power generation. Moreover, the charging time was suppressed during the HPWH operation, which consumes considerable power, to make the backward flow constant throughout the day.

\section{Measurements}

The measurements were carried out from November 18 to 21 and 24 to 28, 2017, during the ENEMANE HOUSE 2017 measurement competition. Students operated the equipment on the premise of maintaining a comfortable indoor environment which was designated as a rule for the competition. The comfortable indoor environment was designated as follows : An air temperature between 21.2 and 25.2 degrees Celsius, a relative humidity between 40 and $70 \%$, a concentration of $\mathrm{CO}_{2}$ of less than $800 \mathrm{ppm}$, and an illuminance of more than $4 \%$ of the whole sky illuminance (10:00-15:00) or more than $200 \mathrm{~lx}(15: 00-18: 00)$. Students also manually operated the HPWH and BT according to the $\mathrm{PV}$ power generation prediction. The purpose was to increase the amount of power consumption from the PV power generation (self-consumed power) and level the reverse power flow.

Figure 4 shows the household electrical load and hot water supply load during the measurements. As a measurement condition, the electrical and hot water supply load assuming three people's lives was imposed every day. Three students stayed inside the house during 9:00-12:00 and 14:00-18:00 and tapped hot water manually. The power load was generated by the power load resistor during the measurement period.

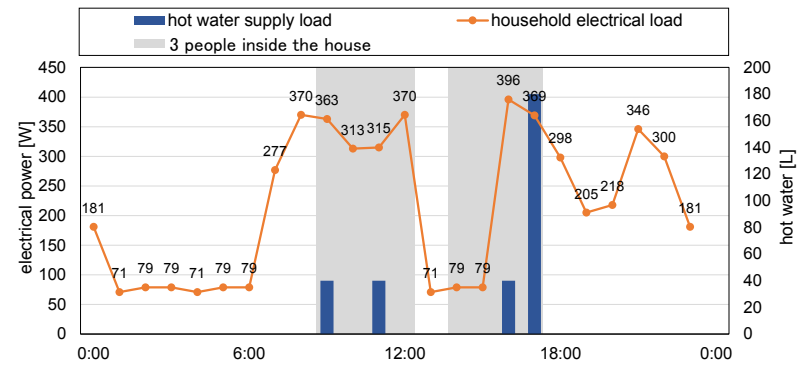

Figure 4. Household electrical load and hot water supply load during the measurements.

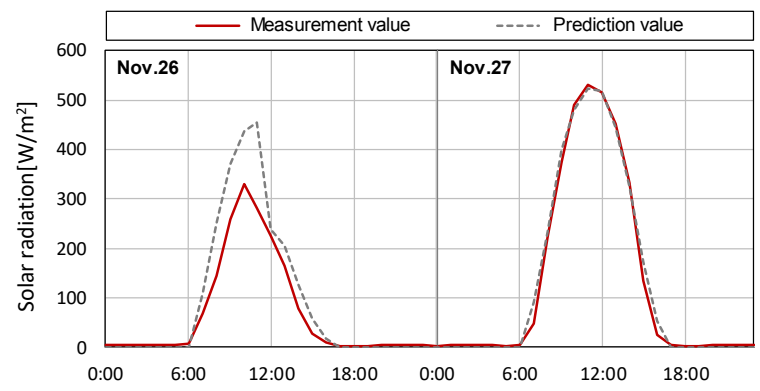

Figure 5. Measurement value and prediction value of solar radiation.

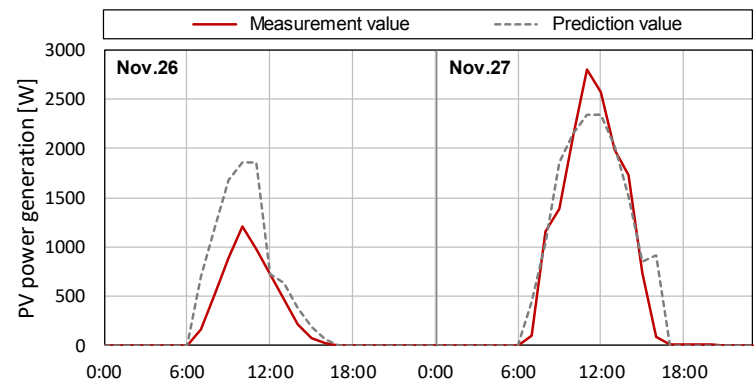

Figure 6. Measurement value and prediction value of PV power generation.

\section{Measurement results}

\subsection{Prediction accuracy of the solar radiation and PV power generation}

Figure 5 shows the measurement value and prediction value of solar radiation. Figure 6 shows the measurement value and prediction value of PV power generation. Comparing the prediction value with the measurement value of $\mathrm{PV}$ power generation, the measurement value was higher on a clear day (Nov.27) and lower on a cloudy day (Nov.26). The difference between the measurement value and the prediction value of PV power generation was larger than that of solar radiation, suggesting that the difference between the two values increased during the process of calculating the PV power generation prediction value. Moreover, during the entire measurement period, the PV power generation efficiency decreased several times a day, suggesting that the shadows of the surrounding objects covered the PV panels during these times. Because PV power generation largely depends on the installation condition of the PV panels, it is suggested that in order to obtain a more accurate prediction, it is necessary to correct the value for each panel installation location. 


\subsection{Energy consumption}

The total energy consumption of air conditioning, hot water supply, ventilation, and lighting during the measurement period was $7.0 \mathrm{kWh}$ per day, an $86 \%$ reduction from the standard value, which is the value of a standard house of similar capacity. The average PV power generation was 10.3 $\mathrm{kWh}$ per day, which means that the test house achieved netzero energy during the measurement competition.

Figure 7 shows the power waveform of the representative days. The operational time of the HPWH on Nov.25 (a clear day) was extended in anticipation of the hot water supply for Nov.26 (a cloudy day). It was able to shorten the operational time of the HPWH without causing the hot water running out on Nov.26. The sales power on Nov.27 was leveled by suppressing the BT charging time during the morning and the HPWH operation. However, because this measurement was carried out during the measurement competition, the target experiment to estimate the effect of the schedule control could not be performed. Instead, the effect was calculated via simulation.

\section{Simulations}

Simulation was conducted to calculate the effect of the schedule control of the HPWH operational starting time, HPWH operational total time, and BT charging time. As an index to evaluate energy self-consumption, the energy selfconsumption rate was set using formula (1). As an index to evaluate the leveling of energy supply and demand, the daily energy load rate was set using formula (2), and the energy results of each condition were compared using the index. self consumption rate

$=\frac{(\mathrm{PV} \text { power generation }- \text { sales power })[\mathrm{Wh}]}{\mathrm{PV} \text { power generation }[\mathrm{Wh}]}$

daily energy load rate

$=\frac{\text { daily avg of (sales power }+ \text { purchase power })[\mathrm{W}]}{\text { daily max of (sales power }+ \text { purchase power })[\mathrm{W}]}$

Table 2 shows the simulation conditions. Table 3 shows the input data for the simulation. The simulation was conducted under totally four cases on the schedule control of HPWH operational starting time, HPWH operational total time, and BT charging time. Nov.25, 26 and 27 were selected as the representative days, when the schedule control was performed satisfactorily, and the input data of the simulation was decided based on the actual measurement values of these three days. For the input data of PV power generation and power consumption except for the HPWH, actual measurement values were used. The initial BT charging amount was set as $3488 \mathrm{Wh}$, which was the measurement value at 0:00 on Nov.25. The charge efficiency, discharge efficiency, and chargable amount of BT were set as $90.5 \%$, $90.5 \%$, and $4.48 \mathrm{kWh}(80 \%$ of the whole capacity of BT) respectively, with reference to the measurement value. In Case 3 and Case 4, in which the HPWH operational starting time and total time were controlled, actual measurement values were used for input data for the HPWH power consumption. However, in Case 1 and Case 2, in which the HPWH operational total time was not controlled, the daily average of the hot water supply amount was calculated from the actual measurement value of the three days and it was set as the hot water supply amount for each day. In Case 2, in

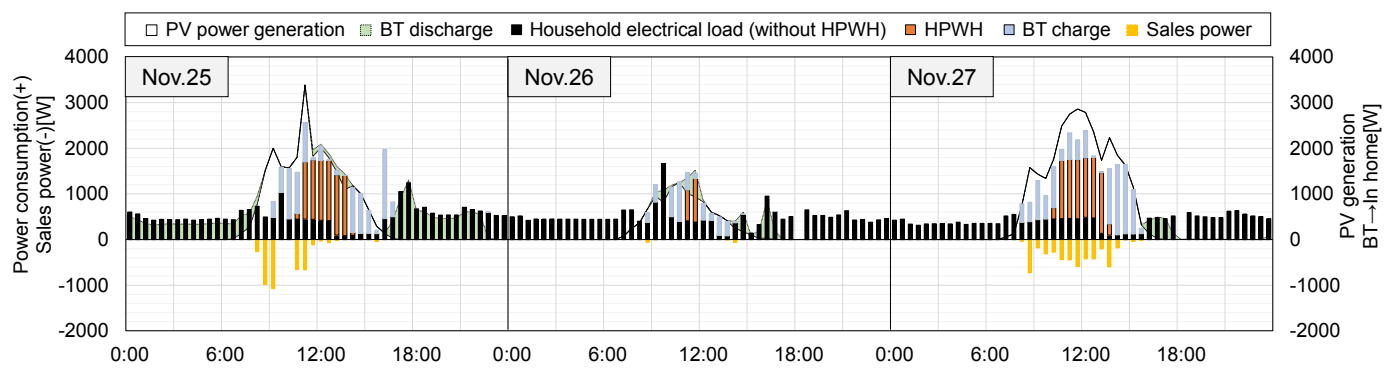

Figure 7. Power waveform of the representative days.

Table 2. Simulation conditions

\begin{tabular}{|c|c|c|c|c|c|}
\hline \multicolumn{2}{|c|}{} & Case 1 & Case 2 & Case 3 & Case 4 \\
\hline \multirow{2}{*}{ HPWH } & Operational starting time control & X & $\checkmark$ & $\checkmark$ & $\checkmark$ \\
\hline & Operational total time control & $X$ & $X$ & $\checkmark$ & $\checkmark$ \\
\hline BT & Charging time control & $X$ & $X$ & $X$ & $\checkmark$ \\
\hline
\end{tabular}

Table 3. Input data for the simulation.

\begin{tabular}{|c|c|c|c|c|}
\hline \multicolumn{3}{|c|}{ Schedule control } & \multicolumn{2}{|l|}{ Input data } \\
\hline \multirow{4}{*}{ HPWH } & $\begin{array}{l}\text { Starting } \\
\text { time }\end{array}$ & Total time & Daily hot water supply amount & Operational time \\
\hline & $\checkmark$ & $\checkmark$ & Actual measurement value & Actual measurement value \\
\hline & $\checkmark$ & $\mathrm{x}$ & \multirow{2}{*}{$\begin{array}{l}3.0 \mathrm{kWh} \text { (the daily average of hot water supply amount } \\
\text { calculated from the actual measurement value of } 3 \text { days) }\end{array}$} & $\begin{array}{l}\text { 10:30 - 13:00 (clear day) } \\
\text { 13:00-15:30 (cloudy day) }\end{array}$ \\
\hline & $\mathrm{X}$ & $\mathrm{X}$ & & $4: 30-7: 00$ \\
\hline \multirow{3}{*}{ BT } & \multicolumn{2}{|c|}{ Charging time } & \multicolumn{2}{|c|}{ Charging amount } \\
\hline & \multirow{2}{*}{\multicolumn{2}{|c|}{$\frac{1}{x}$}} & \multicolumn{2}{|c|}{ Adjust charging amount in order to level the sales power } \\
\hline & & & \multicolumn{2}{|c|}{ Charge whole amount of surplus electric power } \\
\hline
\end{tabular}


which the HPWH operational starting time was controlled, the HPWH operational time was set as 10:30-13:00 (according to the PV power generation) on clear days, and 13:00-15:30 (according to the household electricity load) on cloudy days. In Case 1, in which the operational starting time was not controlled, the operational time was set as 4:30-7:00 every day assuming to use nighttime electricity for HPWH. Regarding the BT schedule control, the charging time was controlled in Case 4 to level the sales power. The charging amount was suppressed within a range in which the BT would be fully charged on Nov.25 and 27 when there was sufficient PV power generation. On the other hand, in Case 1, Case 2 and Case 3, the whole amount of PV power generation was charged to the BT when there was surplus electric power.

\section{Simulation results}

Figure 8 shows the power waveforms under each condition. Figure 9 shows the sales power and purchase power, and figure 10 shows the energy evaluation index under each condition. First, the validity of the simulation was verified by comparing the actual measuement value to Case 4, which simulated the schedule control of the HPWH operational starting time, HPWH operational total time and BT charging time. Next, the energy evaluation index of each condition was compared, and the effect of each schedule control was calculated. The energy evaluation index of the actual measurement value is the value after correcting the power purchase caused by the erroneous BT operation.
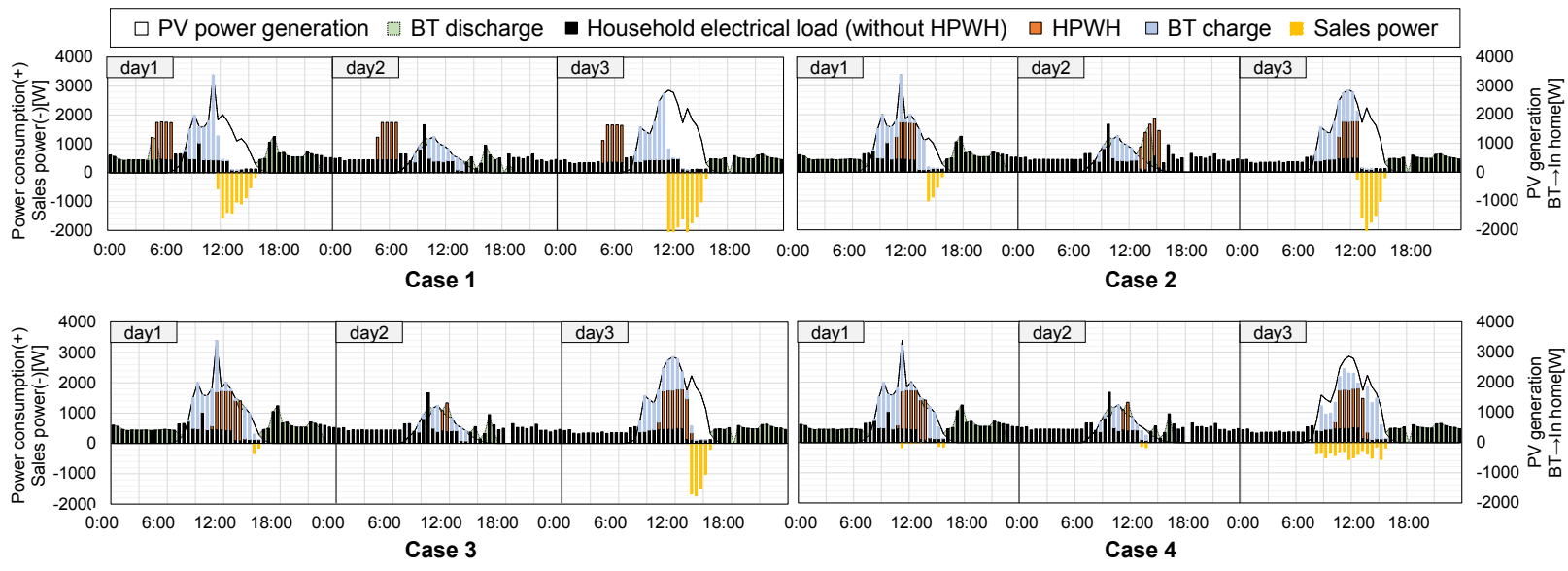

Figure 8. Power waveforms under each condition.

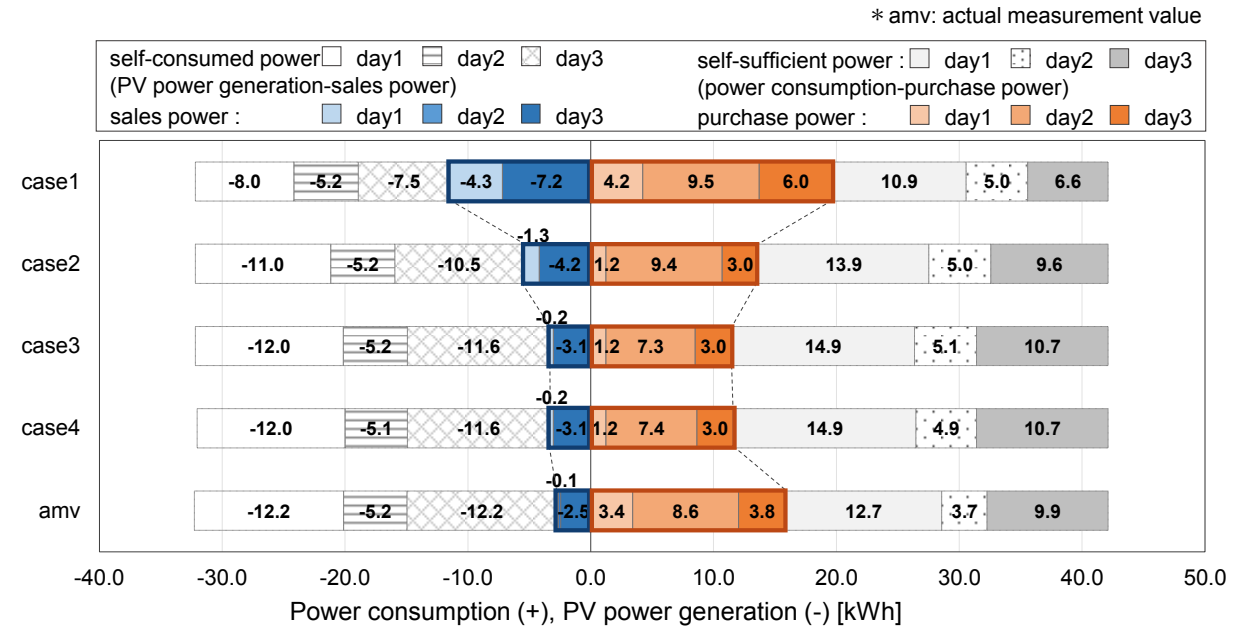

Figure 9. Sales power and purchase power under each condition.
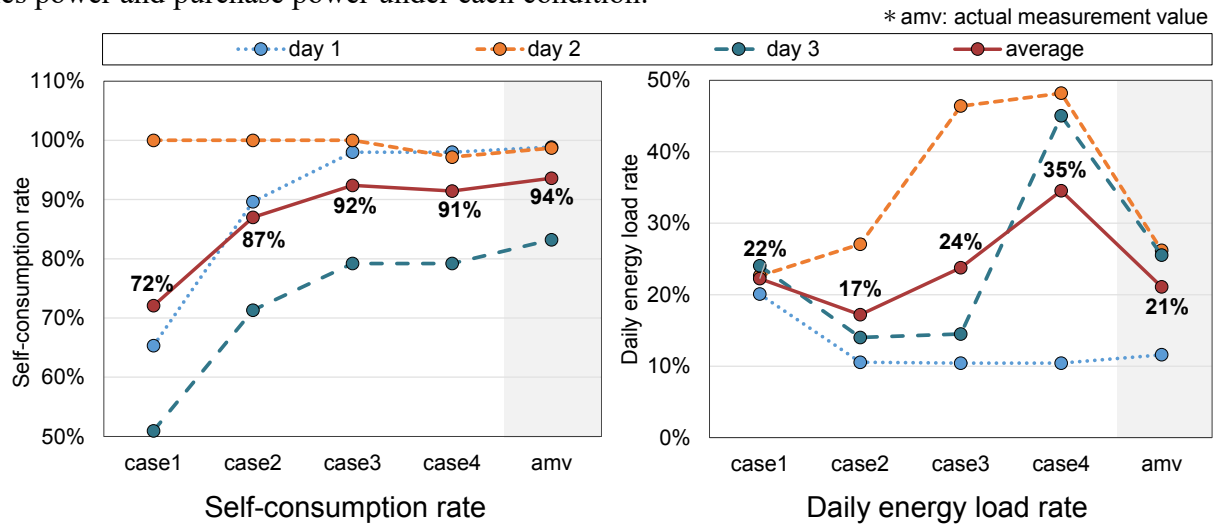

Figure 10. Energy evaluation index under each condition. 


\subsection{Simulation validity}

The simulation results of Case 4 was compared to the actual measurement value to verify the validity of the simulation. The power waveform of Case 4 and actual measurement showed the same behavior, and the sales power and the selfconsumption rate of both conditions were similar. Meanwhile, the purchase power of the actual measurement was larger than that of Case 4 by $1.4 \mathrm{kWh}$ on average. Difficulty in accurate prediction of solar radiation and power consumption in realtime may have caused excessive suppression of the BT charge and led to the increase in the purchase power. Moreover, the daily energy load rate of the actual measurement was less than that of Case 4 by $14 \%$ on average, suggesting the difficulty of BT schedule control in practice. If the prediction accuracy of solar radiation and power consumption increase, leveling reverse power flow may be possible without increasing the amount of purchase power.

\subsection{Effect of schedule control}

First, to understand the effect of the HPWH operational starting time schedule control, Case 1 and Case 2 were compared. On a clear day, the amount of purchase power decreased by $3.0 \mathrm{kWh}$, and the self-consumption rate improved by $20 \%$ or more by using the schedule control. This result indicates the self-consumption effect of the HPWH operational starting time schedule control.

Second, to understand the effect of the HPWH operational total time schedule control, Case 2 and Case 3 were compared. By conducting schedule control, sales power decreased by 1.1 $\mathrm{kWh}$ on a clear day, and purchase power decreased by 2.1 $\mathrm{kWh}$ on a cloudy day. By covering hot water supply of a cloudy day with the HPWH operation on clear a day using PV power generation, it was shown that the purchase power on a cloudy day can be reduced.

Third, to understand the effect of the BT charging time schedule control, Case 3 and Case 4 were compared. Though there was no significant change in purchase power and sales power, the daily energy load rate improved by $11 \%$ on average. Moreover, from the power waveform of Case 4 , it was confirmed that the sales power was leveled compared to that of Case 3. As a result, it was shown that the sales power was leveled using the BT charging time schedule control.

Finally, to calculate the effect when all schedule controls were performed, Case 1 and Case 4 were compared. The selfconsumed power largely increased, and the sales power decreased by $4.1 \mathrm{kWh}$ on a clear day. Purchase power decreased on both clear and cloudy days, and the decrease was $3.0 \mathrm{kWh}$ on a clear day and $2.1 \mathrm{kWh}$ on a cloudy day. The self-consumption rate improved by $19 \%$ and the daily energy load rate improved by $13 \%$. From the aforementioend results, it is suggested that schedule control of the HPWH and BT contribute to self-consumption of surplus power and leveling of power reverse power flow.

\section{Conclusion}

The aim of this study was to acquire knowledge regarding methods of self-consuming surplus power as well as leveling reverse power flow. A net-zero energy house was built, and a
HPWH, whose hot water storage tank stores thermal energy, and a BT, which stores electrical energy, were installed. An equipment operation method termed "schedule control" was proposed and implemented, which operates the HPWH and BT according to solar radiation prediction aiming for selfconsumption and levelling of reverse power flow. An actual measurement was conducted to confirm the demonstration possibility during the competition of ENEMANE HOUSE 2017. Moreover, the effect of schedule control was calculated via simulation. The following conclusions were obtained from the measurement and simulation results.

1) The HPWH schedule control was possible to some extent, but the BT schedule control was difficult in practice with the current prediction accuracy. However, if the prediction accuracy of solar radiation and power consumption improve, leveling reverse power flow by BT schedule control may be possible without increasing the amount of purchase power.

2) It was suggested that the HPWH schedule control was useful for self-consumption and reducing the purchase power on a cloudy day. By controlling operational starting time, the amount of purchase power decreased by $3.0 \mathrm{kWh}$, and the self-consumption rate increased by $20 \%$ or more on a clear day. By controlling operational total time, the hot water supply of a cloudy day was covered with the clear day's HPWH operation using the PV power generation, leading to the decrease in purchase power by $2.1 \mathrm{kWh}$ on a cloudy day. 3) It was suggested that the BT schedule control was useful for smoothing the reverse power flow throughout the day. By using BT schedule control, the daily energy load rate improved by $11 \%$.

Support for this research was provided by Waseda Research Institute for Science and Engineering and Japan Science and Technology (JST), CREST. This work was made possible by "ENEMANE HOUSE 2017" conducted by the Sustainable open Innovation Initiative. Authors would also like to acknowledge the cooperation from related parties and cooperating companies.

\section{References}

1. https://www.enecho.meti.go.jp/category/saving_and_ne w/saving/zeh_report/pdf/report_160212_en.pdf, The Mi nistry of Economy, Trade and Industry [accessed 05.05. 19]

2. Japan Photovoltaic Energy Association, JPEA PV OUT LOOK 2030

3. Japan Photovoltaic Energy Association, JPEA PV OUT LOOK 2050

4. https://www.enemanehouse.jp/index.html, ENEMANE HOUSE Secretariat [accessed 14.12.18]

5. https://www.solardecathlon.gov/, U.S. Department of E nergy, Solar Decathlon [accessed 11.4.19]

6. http://www.jmbsc.or.jp/jp/, Japan Meteorological Busin ess Support Center, Japan [accessed 15.12.17]

7. T. Suzuki, Y. Goto, T. Terazono, S. Wakao, T. Oozeki. Forecast Method of Solar Irradiance with Just-In-Time Modeling. IEEJ Trans.PE, 131, 11, 912-919 (2011)

8. http://k-ichikawa.blog.enjoy.jp/etc/HP/js/sunShineHour Erbs/sse.html, Estimation program of solar power slope solar radiation (Erbs model) [accessed 15.12.17] 